\title{
Second Gradient Models and Concrete Structures
}

\author{
G. Jouan, M. Soufflet, P. Kotronis and F. Collin
}

\begin{abstract}
Damage induces strain localization in quasi-brittle materials such as concrete. In order to correctly simulate this behaviour, it is necessary to introduce a length scale parameter in the continuum model. The second gradient model, a special case of kinematically enriched continua, uses an internal length parameter by taking into account the second order derivatives of the displacements in the virtual power principle. A penalty term is added in the original second gradient finite element formulation in order to improve convergence and to avoid erroneous damage distribution. A three points bending test of a reinforced concrete beam show the performance of the improved second gradient finite element formulation.
\end{abstract}

\section{Introduction}

As a material exhibiting softening, concrete is subject to strain localization. In order to correctly simulate this behavior a model with a length scale parameter is needed. Chambon, Caillerie and Hassan gave a closed form solution for the one dimensional problem of strain localization in a bar with a bilinear type constitutive law in a second gradient continuum [2]. This was soon followed with several applications for plane strain shear banding [4, 14, 17, 22], mostly in soils. Similar approaches were also recently used in the framework of damage mechanics combined with homogenization techniques by $\mathrm{Li}[15,16]$, see also $[10,11,13,23]$ for application in concrete structures.

\footnotetext{
G. Jouan · M. Soufflet $\cdot$ P. Kotronis (四)

Ecole Centrale de Nantes, Université de Nantes, CNRS UMR 6183,

GeM (Institut de Recherche en Génie Civil et Mécanique),

1 rue de la Noë, BP 92101, 44321 Nantes, France

e-mail: Panagiotis.Kotronis@ec-nantes.fr

F. Collin

Département Argenco, Institut de mécanique et Génie Civil, Université de Liège, Bât. 52, 9 Allée de la Découverte, 4000 Liège, Belgium

e-mail: f.collin@ulg.ac.be 
In this paper, it is shown that the original finite element formulation adopted in a previous work of the authors [11] presents some numerical difficulties to correctly simulate damage localization problems. The original finite element of Matsushima et al. [17] is thus improved by adding a penalty term, following previous works by Fernandes [6] for plasticity problems. The ability of the improved model to better simulate strain localization in concrete is studied with a three points bending test of a reinforced concrete beam.

\section{Second Gradient Model}

Considering a body of domain $\Omega$ and of boundary $\Gamma$, the general formulation of a second gradient model using the virtual power principle can be written as follows $[2,17]$ :

$$
\int_{\Omega}\left(\sigma_{i j} u_{i, j}^{\star}+\Sigma_{i j k} u_{i, j k}^{\star}\right) d \Omega=\int_{\Gamma}\left(p_{i} u_{i}^{\star}+P_{i} D u_{i}^{\star}\right) d \Gamma,
$$

where $\sigma_{i j}$ is the macro stress (the classical second order stress tensor), $\Sigma_{i j k}$ the double stress (a third order tensor) and $p_{i}$ and $P_{i}$ respectively the first (classical) and second order surface traction (first order tensors).

In linear elasticity, the constitutive law for $\sigma_{i j}$ depends as usual on the first gradient of the displacements, while $\Sigma_{i j k}$ is a function of the second gradient of the displacements [19]. Coupling between the first and second gradient parts is possible, see for example [3, 7, 12]. Chambon and co-workers considered mainly cases with full decoupling of the first and second gradient parts: nonlinear laws, independent of $\Sigma_{i j k}$ and $u_{i, j k}$ for the first gradient part and an elastic linear isotropic law for the second gradient part $[5,14,17,20]$. It should be highlighted however that the introduction of damage on the second gradient part has been studied by different authors $[12,15$, 16, 23]. In [12] and for a $1 \mathrm{D}$ case, it is shown that a carefully formulated coupling law leads to an a priori control of the width evolution (constant, increase or decrease) of the localisation zone.

\section{Finite Element Formulation}

\subsection{The Original Mixed Formulation}

One way to circumvent the difficulties of the necessary $C^{1}$ continuity is to adopt a mixed formulation and to interpolate the gradient independently from the displacement field [17, 21]. More specifically, the displacement field $u_{i}$ and its gradient noted $v_{i j}$ are both interpolated with $C^{0}$ functions since only first order derivatives appear in the weak formulation provided either by the virtual power principle of a general 
micromorphic media with a kinematic constrain [3] or by integration of the strong form of the equilibrium equations [21]. In the former case, we can directly write:

$$
\int_{\Omega}\left(\sigma_{i j} u_{i, j}^{\star}+\lambda_{i j}\left(v_{i j}^{\star}-u_{i, j}^{\star}\right)+\Sigma_{i j k} v_{i, j k}^{\star}\right) d \Omega=\int_{\Gamma}\left(p_{i} u_{i}^{\star}+P_{i} v_{i j}^{\star} n_{j}\right) d \Gamma
$$

with the added kinematic constraint (in weak form) :

$$
\int_{\Omega} \lambda_{i j}^{\star}\left(v_{i j}-u_{i, j}\right) d \Omega
$$

where $\lambda_{i j}^{\star}$ is the field of Lagrange multipliers associated with the kinematic constraint. For the second gradient model, Matsushima et al. [1, 17] originally developed a 9-nodded finite element with the displacement field interpolated by biquadratic functions of the serendipity type and the gradient field by bilinear functions. Lagrange multipliers are constant on the element while numerical integration is performed using a classical Gauss scheme [1]. The numerical performance of this formulation is tested hereafter using a three points bending test of a reinforced concrete beam.

\subsection{A Three Points Bending Test of a Reinforced Concrete Beam}

The concrete beam has the following geometrical characteristics: thickness $b=$ $200 \mathrm{~mm}$, height $h=500 \mathrm{~mm}$ and span $5000 \mathrm{~mm}$. The tested beam and the steel reinforcement are shown in Fig. 1.

The finite element mesh consists of 5180 elements, 4148 of which are second gradient elements and 1032 truss elements representing the horizontal reinforcement. The average size of the concrete elements is of $0.02 \mathrm{~m} \times 0.035 \mathrm{~m}$. The two supports (the two points at the bottom of the specimen, see Fig. 1) are blocked vertically while the right support is also blocked horizontally. For the finite element calculations, monotonically increased displacements are applied at the upper part of the beam through an elastic plate, which is very stiff compared to the other materials [11].

At both supports at the bottom of the beam and on the upper part, where the displacements are applied, an elastic linear law is introduced to prevent any artificial numerical damage. A classical damage mechanics law is used for the first gradient constitutive law [18]. An isotropic linear elastic constitutive law is adopted for the second gradient part depending on a single material parameter. No coupling is assumed between the first and the second gradient constitutive laws. An elastic perfectly plastic law is used for the reinforcement and a perfect bond is assumed.

Figure 2 shows the damage distribution in the entire beam as well as two close ups. It can be observed that in the localization bands and inside certain finite elements some integration points present an increasing damage variable while others are unloading leading to serious convergence problems. 

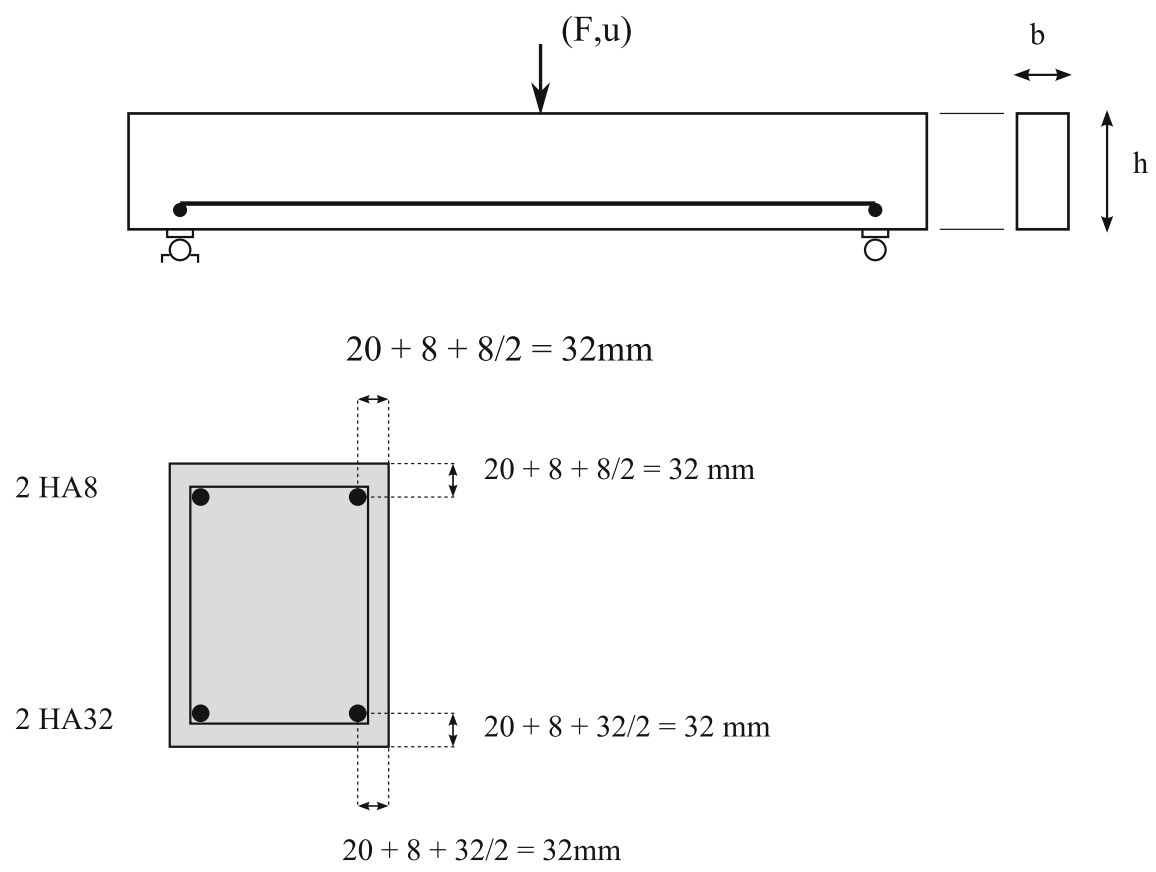

Fig. 13 point bending test: beam dimensions and steel reinforcement $[8,9]$
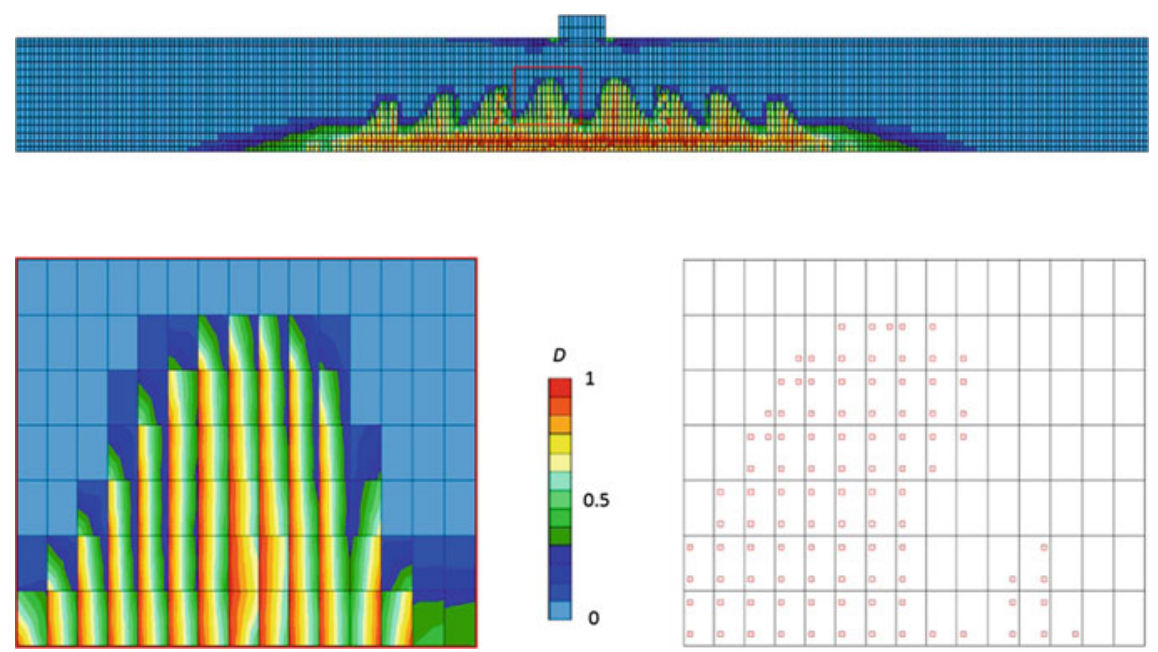

Fig. 2 Damage distribution in a three points beam test (top figure). Zoom on damage oscillation problems (left figure) and loading integration points (red rectangles correspond to integration points with an increasing damage variable, right figure) 

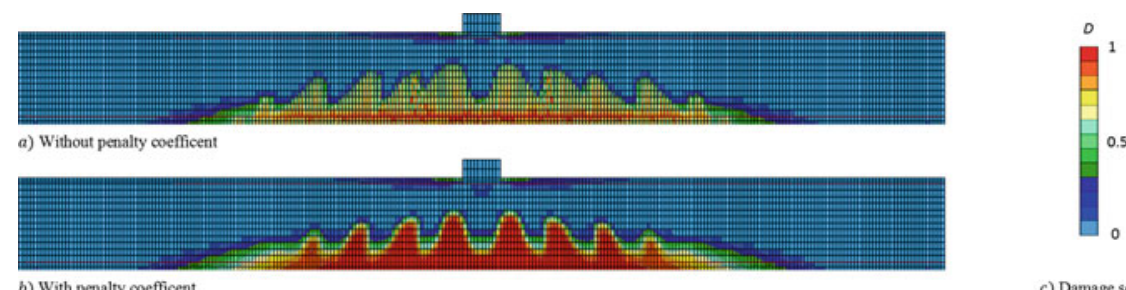

b) With penalty coefficent

Fig. 33 point bending test: damage distribution for an imposed displacement of $6 \mathrm{~mm}$ a without and $\mathbf{b}$ with a penalty factor

\subsection{Addition of a Penalty Term}

A way to improve the numerical performance of the original mixed second gradient finite element formulation is to add a penalty term to enforce the kinematic constraint (while keeping the Lagrange multipliers) [10]. A similar approach was proposed by Fernandes et al. [6] in the context of plasticity. Noting $C$ the penalty factor, the weak formulation of the problem becomes:

$$
\begin{gathered}
\int_{\Omega}\left(\sigma_{i j} u_{i, j}^{\star}+\lambda_{i j}\left(v_{i j}^{\star}-u_{i, j}^{\star}\right)+C\left(v_{i j}^{\star}-u_{i, j}^{\star}\right)\left(v_{i j}-u_{i, j}\right)+\Sigma_{i j k} u_{i, j k}^{\star}\right) d \Omega=\int_{\Gamma}\left(p_{i} u_{i}^{\star}+P_{i} v_{i j, k}^{\star} n_{k}\right) d \Gamma \\
\int_{\Omega} \lambda_{i j}^{\star}\left(v_{i j}-u_{i, j}\right) d \Omega
\end{gathered}
$$

The three points bending test of section is modelled here using the second gradient finite element with the added penalty term. Figure 3 gives the damage distribution corresponding to an imposed displacement $U=6 \mathrm{~mm}$ without and with a penalty factor. It is clear that the introduction of the penalty factor improves the numerical performance of the model and results to a more smooth and continuous damage distribution.

\section{Conclusions}

Following previous works $[11,13]$, the second gradient model is used as a regularization method for concrete structures in the context of damage induced strain localization. The performance of the $2 D$ second gradient finite element is improved by introducing an additional penalty term in the Lagrangian mixed formulation. An example is provided considering a reinforced concrete beam. 


\section{References}

1. Bésuelle, P.: Implémentation d'un nouveau type d'élément fini dans le code lagamine pour une classe de lois á longueur interne. Technical report, Laboratoire Sols, Solides Structures, Grenoble, France (2003). Rapport d'activité

2. Chambon, R., Caillerie, D., Hassan, N.E.: One-dimensional localisation studied with a second grade model. Eur. J. Mech. A/Solids 17(4), 637-656 (1998). doi:10.1016/S09977538(99)80026-6

3. Chambon, R., Caillerie, D., Matsuchima, T.: Plastic continuum with microstructure, local second gradient theories for geomaterials: localization studies. Int. J. Solids Struct. 38(4647), 8503-8527 (2001). doi:10.1016/S0020-7683(01)00057-9

4. Collin, F., Chambon, R., Charlier, R.: A finite element method for poro mechanical modelling of geotechnical problems using local second gradient models. Int. J. Numer. Methods Eng. 65(11), 1749-1772 (2006)

5. Collin, F., Caillerie, D., Chambon, R.: Analytical solutions for the thick-walled cylinder problem modeled with an isotropic elastic second gradient constitutive equation. Int. J. Solids Struct. 46(2223), 3927-3937 (2009). doi:10.1016/j.ijsolstr.2009.05.017

6. Fernandes, R., Chavant, C., Chambon, R.: A simplified second gradient model for dilatant materials: theory and numerical implementation. Int. J. Solids Struct. 45(20), 5289-5307 (2008). doi:10.1016/j.ijsolstr.2008.05.032

7. Fleck, N., Hutchinson, J.: Strain gradient plasticity. Adv. Appl. Mech. 33, 295-361 (1997)

8. Ghavamian, S., Carol, I., Delaplace, A.: Discussions over meca project results. Revue Franaise de Génie Civil 7(5), 543-581 (2003)

9. Jason, L.: Réponse au benchmark statique monotone du projet national ceos.fr (2008). Rapport CEA SACLAY, DM2S/SEMT/LM2S, Rapport ANR MEFISTO

10. Jouan, G.: Modélisation numérique de la localisation des déformations dans le béton avec un modèle de second gradient. Ph.d., Ecole Centrale de Nantes, Université de Liège (cotutelle) (2014). http://bictel.ulg.ac.be/ETD-db/collection/available/ULgetd-11042014-112001/ (in French)

11. Jouan, G., Kotronis, P., Collin, F.: Using a second gradient model to simulate the behaviour of concrete structural elements. Finite Elem Anal Des 90, 50-60 (2014). doi:10.1016/j.finel. 2014.06.002

12. Kotronis, P.: Stratégies de modélisation de structures en béton soumises à des chargements sévères. H.D.R. (Habilitation Diriger des Recherches), Université Joseph-Fourier-Grenoble I (2008). http://tel.archives-ouvertes.fr/tel-00350461

13. Kotronis, P., Chambon, R., Mazars, J., Collin, F.: Local second gradient models and damage mechanics: application to concrete. In: 11th International Conference on Fracture, Turin, Italy, Org. ICF, cd, paper, vol. 5712, pp. 20-25 (2005)

14. Kotronis, P., Al Holo, S., Bésuelle, P., Chambon, R.: Shear softening and localization: modelling the evolution of the width of the shear zone. Acta Geotech. 3(2), 85-97 (2008)

15. Li, J.: A micromechanics-based strain gradient damage model for fracture prediction of brittle materials-part i: Homogenization methodology and constitutive relations. Int. J. Solids Struct. 48(24), 3336-3345 (2011)

16. Li, J., Pham, T., Abdelmoula, R., Song, S., Jiang, C.: A micromechanics-based strain gradient damage model for fracture prediction of brittle materials-part ii: Damage modeling and numerical simulations. Int. J. Solids Struct. 48(24), 3346-3358 (2011)

17. Matsushima, T., Chambon, R., Caillerie, D.: Large strain finite element analysis of a local second gradient model: application to localization. Int. J. Numer. Methods Eng. 54(4), 499$521(2002)$

18. Mazars, J.: Application de la mécanique de l'endommagement au comportement non linéaire et à la rupture du béton de structure. Université Pierre et Marie Curie, Paris VI, Thèse de doctorat d'état (1984)

19. Mindlin, R.: Second gradient of strain and surface-tension in linear elasticity. In. J. Solids Struct. 1(4), 417-438 (1965) 
20. Pardoen, B., Levasseur, S., Collin, F.: Using local second gradient model and shear strain localisation to model the excavation damaged zone in unsaturated claystone. Rock Mech. Rock Eng. 48(2), 691-714 (2014)

21. Shu, J., King, W., Fleck, N.: Finite elements for materials with strain gradient effects. Int. J. Numer. Methods Eng. 44(3), 373-391 (1999)

22. Sieffert, Y., Al Holo, S., Chambon, R.: Loss of uniqueness of numerical solutions of the borehole problem modelled with enhanced media. Int. J. Solids Struct. 46(17), 3173-3197 (2009)

23. Yang, Y., Misra, A.: Micromechanics based second gradient continuum theory for shear band modeling in cohesive granular materials following damage elasticity. Int. J. Solids Struct. 49(18), 2500-2514 (2012) 